Escuela de Ciencias Sociales y Humanidades, UNED, C.R. URL: http://investiga.uned.ac.cr/revistas/index.php/espiga/index

\title{
Redescubriendo la teología de la cruz de Martín Lutero en el contexto de la teología de la liberación
}

Martin N. Dreher*

\author{
Recibido: 06 de mayo, 2016 - Aceptado: 29 de marzo, 2017
}

\section{RESUMEN}

A las radicalidades de la Reforma pertenece la nueva imagen de Dios que Lutero presentó en $L a$ disputación de Heidelberg y que siguió determinando su teología. Dios tiene la cara del Crucificado y mira radicalmente abajo (Magnificat). Sin embargo, el luteranismo representó una doctrina de la justificación que dejó de lado la intención central de Lutero. El objetivo de este artículo es enseñar cómo la teología de la cruz de Lutero se puso de relieve nuevamente en el diálogo con la teología de la liberación en el contexto latinoamericano.

Palabras claves: teología de la Reforma, imagen de Dios, doctrina de la justificación, teología de la cruz, teología de la liberación.

Formato de citación según APA

Dreher, M. N. (2017). Redescubriendo la teología de la cruz de Martín Lutero en el contexto de la teología de la liberación. Revista Espiga, 16(33), 61-76. DOI: http://dx.doi. org/10.22458/re.v16i33.1764

\section{Formato de citación según Chicago}

Dreher, Martin N. «Redescubriendo la teología de la cruz de Martín Lutero en el contexto de la teología de la liberación». Revista Espiga, 33 (2017): 61-76. DOI: http://dx.doi. org/10.22458/re.v16i33.1764

* Doctor en Teología, 1978. Profesor de la Historia eclesiástica y Historia de los dogmas en La Escola Superior de Teología (EST) in São Leopoldo, Brasil, desde 1995 Profesor de la Historia en la Universidade do Vale do Rio dos Sinos, São Leopoldo, Brasil, emérito desde 2011. Brasil. martindreher@terra.com.br 
El 9 de noviembre de 1545, Bartolomé de las Casas escribió una carta al rey Felipe de España, en la cual hacía énfasis que las «herejías» de los luteranos no eran tan malas, comparadas con lo que se hizo contra los indígenas, «ya que la herejías Luteranas no han dejado de lado nuestra fe inmaculada y firme, ni han dejado de orar a nuestro Dios, el Cristo crucificado» ${ }^{1}$.

Aunque no tengo conocimiento de si alguna vez Bartolomé de las Casas trató de nuevo con los luteranos, lo que importa es que desde la lejanía de América Latina fue capaz de identificar la preocupación teológica central de la Reforma luterana: el Dios crucificado. Se caracteriza, pues, la preocupación central de toda auténtica teología: el Dios crucificado que se destaca por su manifestación en la crucifixión (epifanía) como un ser humano.

Bartolomé de las Casas no encontró oyentes en su tiempo. Aunque Lutero inicialmente atrajo partidarios precisamente a causa de su teología de la cruz, su teología gradualmente se redujo a la doctrina de la justificación y su preocupación central para la teología de la cruz se vio marginada. Este desarrollo (probablemente debido a Melanchthon) no se ha alcanzado hasta nuestros días, a pesar de la investigación fundamental llevada a cabo por Walther voxn Loewenich ${ }^{2}$ y otras iniciativas tempranas de Johann Georg Hamann (1730-1788) y Sören Kierkegaard (1951)3.

Aunque Werner Elert y Paul Althaus, por ejemplo, hicieron referencia en sus obras sobre la teología de la cruz, no se le dio la debida importancia, a pesar de las exhortaciones de Ernst Käsemann. ${ }^{4}$ Como era de esperar, la recepción de Bonhoeffer en América Latina ha sido más fuerte que en Alemania.

Nuestro objetivo es mostrar cómo y por qué la preocupación de Lutero llegó a jugar un papel importante en América Latina. El redescubrimiento del Dios crucificado, junto con el Sacerdocio Universal de todos los creyentes, pudo dar lugar a una renovación de los luteranos en todo el mundo.

\section{La Iglesia Luterana en Brasil y el surgimiento de la teología de la liberación}

Vengo de una iglesia luterana de inmigrantes en Brasil, con una historia que se remonta a 1824. Hasta 1889 éramos una iglesia de pequeños propietarios de tierras, que constituía una minoría y tratados como tal. Fuimos de los primeros protestantes que se instalaron en Brasil, un país inmerso en tradiciones de diferentes países del mundo, Portugal, India, África y Nuevos Cristianos (judíos). Solo después de la Segunda Guerra Mundial, gradualmente fuimos dejando nuestro estatus cultural marginado y buscamos convertirnos enteramente en Latinoamericanos.

1. Juan Friede, Bartolomé de las Casas, precursor del anticolonialismo: Su lucha y su derrota (México: Siglo XXI, 1974), 171s. Cito de la traducción alemana de Hans Jürgen Prien, Die Geschichte des Christentums in Lateinamerika (Gottinga: Vandenhoeck y Ruprecht, 1978), 175.

2. Luthers Theologia Crucis (Wittenberg: Luther Verlag, 5. ed. 1967).

3. Einübung im Christentum (Düsseldorf und Köln: Eugen Diederichs Verlag, 1951).

4. Der Ruf der Freiheit (Tubinga: J.C.B.Mohr, Paul Siebeck, 4. ed. 1963). 
En marzo de 1966, cuando empecé mis estudios de teología en Sao Leopoldo, la teología aún estaba dominada por nombres reconocidos. Algunos afirmaban ser de Bultmann o Barthians y unos pocos atraídos por Ernst Käsemann. No obstante, para aquellos de nosotros que estábamos empezando nuestros estudios teológicos, los conflictos entre el gran «Bs» parecía irrelevante. Mi generación ya no podía hablar de la formación de escuelas teológicas claramente definidas. ¿No había alternativas? ¿Teníamos miedo del debate político?

A través de nuestros profesores, la mayoría procedentes de Alemania, oímos ecos del debate teológico en Europa, como la «Teología Política», por el teólogo católico Johann Baptist Metz. ${ }^{5}$ También había un grupo formado en torno a Trutz Rendtorff ${ }^{6}$, pero sin una confrontación entre ellos.

Hubo debates sobre la secularización (Gogarten); a teología de «Dios-está-muerto» fue desarrollado (Altizer und Hamilton ${ }^{8}$ ); unos eran ocupados de la ciudad secular (Harvey $\operatorname{Cox}^{9}$ ); ¿Podría la teología seguir adelante después de Auschwitz? (Dorothee Sölle ${ }^{10}$ ). Discusiones que vendrían a generar un importante ejercicio en el desarrollo del autocriticismo de la teología alemana.

Wolfhart Pannenberg desarrolló una «teología de la historia» como alternativa a la teología de Bultmann, que fue bien recibida por los conservadores y rechazada por los Barthians.

Otro movimiento contra Bultmann y Barth, fue llamado «No otro Evangelio», y surgió en Alemania. Fue el precursor de una fuerte tendencia evangélica que pronto se manifestó en la iglesia y fue confundida con la teología arminiana. Este arminianismo fue traído a Brasil por los pastores luteranos de los Estados Unidos. Cabe decir que las iglesias de las llamadas «Misiones Protestantes» (presbiterianos, metodistas, bautistas) se inclinaban cada vez más hacia una teología influenciada por la política de derecha de América del Norte, este fue el tiempo de la Guerra Fría. Para estar seguros, se produjeron debates con colegas de procedencias pietistas, $u$ otros convertidos por los pastores de la Liga de Oración de la Misión Mundial. Sin embargo, las discusiones, se centraron más en las cuestiones éticas que en las diferencias teológicas. Pasábamos por un período de crisis

5. Junto con Jürgen Moltmann und Willi Oelmüller. Kirche im Prozess der Aufklärung: Aspekte einer neuen «politischen Theologie» (München: Chr. Kaiser Verlag - Mainz: Grünewald Verlag, 1970).

6. Trutz Rendtorf y Heinz Eduard Tödt, ed., Theologie der Revolution - Analysen und Materialien, (Francfort de Mena: Suhrkamp Verlag, 4. ed. 1970).

7. Friedrich Gogarten, Verhängnis und Hoffnung der Neuzeit. Die Säkularisierung als theologisches Problem (München und Hamburg: Siebenstern, 1966).

8. Thomas J.J. Altizer y William Hamilton, A Morte de Deus- Introdução à Teologia Radical (Rio de Janeiro: Editora Paz e Terra, 1967). [Radical Theology and the Death of God, 1966].

9. Harvey Cox, A Cidade do Homem: A secularização e a urbanização na perspectiva teológica (Rio de Janeiro: Pax e Terra, 1968). [The Secular City, 1965]. La editorial Paz e Terra, fundada en julio de 1966, publicó textos en teología evangélica, que no fueron publicados por las editoriales relacionadas con la iglesia en Brasil, por ser considerados «peligrosos» en el contexto del golpe militar de 1964. La editorial fue de las primeras en difundir las ideas de la teología de liberación en Brasil. En 1966, 16 títulos fueron publicados, y en 1968, 25 títulos.

10. Dorothee Sölle, Stellvertretung: Ein Kapitel Theologie nach dem «Tode Gottes» (Gütersloh: Mohn, 1965). 
política. Nuestros sueños se habían frustrado en una etapa temprana, gracias al golpe militar de estado en 1964.

A partir de 1968 se vivía con gran miedo, ya que la dictadura había emitido un decreto, mediante el cual el Presidente de la República ordena al Congreso Nacional y las legislaturas de los estados suspenderse temporalmente, se nombraron interventores federales para ejecutar los estados y municipios claves y se prohíben las reuniones políticas, se establece una estricta censura política a la prensa y manifestaciones culturales. En estos difíciles años, un libro se convirtió en una importante fuente para nosotros, como lo fue Resistencia y Sumisión de Dietrich Bonhoeffer. Este libro fue traducido por el luterano judío Ernst Bernhoeft, quien había escapado de la Alemania nazi a Brasil, y se convirtió en maestro de las escuelas parroquiales luteranas, mas no aceptado como pastor. Esto fue negado debido a la influencia de la Iglesia Evangélica Alemana, a través del Ministerio Eclesiástico de Asuntos Exteriores y su Obispo Theodor Heckel. Ernst Bernhoeft más tarde trabajaría en la Iglesia Anglicana en Brasil. ${ }^{11}$

En 1966 Richard Shaull, profesor en el Seminario Presbiteriano en Campinas (SP), presentó la «Teología de la Revolución» en la Conferencia del Consejo Mundial de Iglesias en Ginebra. ¿Cómo se puede ser cristiano en una situación revolucionaria como la de América Latina? Su libro Transformaciones profundas a la luz de una Teología Evangélica ${ }^{12}$ ayudarían a responder esa pregunta. El libro fue publicado por la Editorial Franciscana en Brasil, debido a que ninguna editorial evangélica tuvo el valor de hacerlo. Este mismo año llegó otro importante libro: Teología de la Esperanza por Jürgen Moltmann, en el cual se reflexiona sobre las consecuencias de una escatología cristiana para la acción y vida teológica en América Latina. ${ }^{13}$

La Iglesia Evangélica de Confesión Luterana en Brasil fue una «iglesia de alemanes»; más del 70\% de sus pastores eran extranjeros. Desde la Segunda Guerra Mundial, Brasil ha convertido poco a poco su horizonte hacia una iglesia luterana. La situación de la mayoría de la población del llamado «Tercer Mundo» también comenzó a ganar importancia en aquellos años. La Conferencia Noreste inició el tema «Cristo y el Proceso Revolucionario Brasileño ${ }^{14}$, el cual llegó a ser de gran importancia para los protestantes brasileños. Nuestras circunstancias nos instan a cuestionar el lugar teológico en América Latina, y lo que sería nuestro papel después de haber terminado nuestros estudios.

La elección del Papa Juan XXIII y el Concilio Vaticano II fueron hitos posteriores y sus encíclicas Mater et Magistra (1961) and Pacem in Terris (1963), así como su discurso sobre «la Iglesia de los Pobres», eran de importancia fundamental para los compromisos políticos y sociales del catolicismo en América Latina, pero también tuvo repercusiones en el protestantismo.

11. Dietrich Bonhoeffer, Resistência e submissão (Rio de Janeiro: Paz e Terra, 1968). Con respecto a Bernhoeft véase Oswaldo Kickhofel, Ernesto João Bernhoeft. Uma vida de fé, abnegação e júbilo - 1917-2001 (Montenegro: s.e.,2011).

12. Petrópolis: Vozes, 1966.

13. Jürgen Moltmann, Theologie der Hoffnung: Untersuchungen zur Begründung und zu den Konsequenzen einer christlichen Eschatologie (München: Chr. Kaiser Verlag, 6. ed., 1966).

14. Confederação Evangelica do Brasil (Ed.), A Conferencia do Nordeste: Cristo e o Processo Revolucionario Brasileiro, 2 Vol. (Rio de Janeiro: Editora Loqui, 1962). 
Esto coincidió con el movimiento revolucionario en toda América Latina, cuando Fidel Castro en 1959 puso a fin al régimen de Fulgencio Batista en Cuba, quien apoyaba los negocios promovidos por los Estados Unidos, como los casinos, la prostitución. Después de 1959, el movimiento de izquierda latinoamericano creía que los movimientos guerrilleros tendrían al final su oportunidad y que el marxismo era el único camino hacia la libertad y el socialismo. Los modelos fueron Camilo Torres y Ernesto Che Guevara, quienes al morir en 1966 y 1967, la primera etapa de los movimientos llegaban a su fin. Fidel, Camilo y el Che eran parte de nuestro aprendizaje, aunque sus nombres solo podían ser susurrados. De 1964 Brasil estaba bajo una dictadura militar, con un régimen de seguridad nacional que comenzó en 1968. Las esperanzas de muchos se dirigieron hacia el «modelo chileno», el cual fue introducido en Chile en 1970-1973, en Perú 1968 (Alvarado), Argentina 1971, (Lanusse y Perón) y en Bolivia en 1971 (Torres). ${ }^{15}$

Sin embargo, después de 1968 una serie de golpes militares, fueron llevados a cabo, y se implementaron «regímenes de seguridad nacional», y pusieron fin a los sueños de aquellos que afirmaban que el socialismo se introduciría por la paz. La línea dura de los militares implementaron este tipo de régimen en Brasil; y luego exportado a los países vecinos de Bolivia (1971), Uruguay (1973), Chile (1973), Perú (1975) y Argentina (1976). El 11 de septiembre de 1973, el Palacio Presidencial en Santiago de Chile, fue bombardeado y el presidente Allende se quitó la vida. Al día siguiente, se dice que el secretario de Estado de EE.UU, Henry Kissinger había dicho, si una nación no es capaz de elegir a sus líderes correctamente, los demás países deben ayudar a encontrar un mejor gobierno. Este «mejor gobierno» fue el de Augusto Pinochet Ugarte.

Alguna teología seria fue creada, para asegurar que el Pueblo de Dios fuera capaz de sobrevivir en el desierto sin renunciar a su esperanza del Reino. En el año 1965 los sacerdotes católicos Gustavo Gutiérrez, Juan Luis Segundo, Segundo Galilea, entre otros, empezaron a formular sus principales tesis entre 1965 y 1970. Al mismo tiempo en Montevideo se creaba el movimiento ISAL de la Iglesia y Sociedad en América Latina, el cual inició, con la investigación de la teoría de la dependencia y la sociología de la liberación. Esta se convirtió en una influyente publicación periódica «Cristianismo y Sociedad» (1962).

Richard Shaull percibe estas tendencias revolucionarias en América Latina y se dispone a interpretarlas a la luz del Evangelio, en su libro As transformações profundas à la luz de uma teología Evangélica ${ }^{16}$, donde se centra en las cuestiones de violencia y revolución. También Emilio Castro, Julio de Santa Ana, José Miguez Bonino y Rubén A. Alves representaron la nueva teología de la liberación en el lado evangélico. La mayoría no fueron aceptados por sus iglesias; sin embargo, sus voces fueron escuchadas por el Consejo Mundial de Iglesias.

Lo que se estaba gestando en América Latina tuvo algún efecto en nuestros estudios en São Leopoldo. Entre los años 1966 y 1970 la exégesis bíblica, la ética, la historia de la

15. Ver Martin N. Dreher, A lgreja Latino-Americana no Contexto Mundial (São Leopoldo: Sinodal, 1999), 193-194.

16. Petrópolis: Vozes, 1966 
iglesia y la teología práctica comenzaron a tomar temas latinoamericanos cada vez más en cuenta, gracias a los esfuerzos de nuestros maestros, como Gerhard Barth, Joachim Fischer, Lindolfo Weingärtner, Hans Strauss, Bertholdo Weber, Harm Alpers, Gottfried Brakemeier y Nelson Kirst. Teníamos miedo y la sospecha de que los operativos de los agentes de la policía secreta (DOPS and CNI) estarían entre nosotros. Años más tarde, el portavoz del Gobierno mostraría a los presidentes de la iglesia luterana un archivo clasificado con información de los estudiantes de la escuela. El dictador Ernesto Geisel menciona la escuela:

En el seminario en Sao Leopoldo, en el estado de Rio Grande do Sul, hay una gran cantidad de infiltración de izquierda, con el apoyo de los pastores alemanes. Al igual que muchos sacerdotes católicos, también se han aprovechado de los problemas de la reforma agraria y de la distribución de la tierra a los agricultores pobres. ${ }^{17}$

Y así muchas congregaciones fueron consideradas comunistas.

La teología de la liberación se expandió ampliamente entre 1970 y 1975, realizándose una serie de congresos, el primero y con el impacto más profundo fue en El Escorial (8-15 de julio, 1972). Los partidarios y los oponentes posteriores de la teología de la Liberación estuvieron presentes. ${ }^{18}$ Durante el congreso en México en 1975, se formó un amplio frente de teólogos de la liberación, pero los acontecimientos políticos no hicieron posible realizar reuniones adicionales.

Las primeras publicaciones importantes también aparecieron en estos años; por ejemplo, Gustavo Gutiérrez con Teología de la liberación $(1971)^{19}$; Juan Luis Segundo con De la sociedad a la teología (1970) y la Liberación de la teología $(1975)^{20} ; \mathrm{H}$. Assmann Opresión y liberación, Un reto para los cristianos $(1971)^{21}$ y Teología de la praxis de la liberación (1973) 22; Rubem Alves A. Theology of Human Hope (1969)23; José Miguez Bonino con Teología en el contexto de la liberación (1975) y Fe en la búsqueda de la Eficacia $(1976)^{24}$. Después de Medellín, una segunda generación de autores apareció, entre ellos, Severino Croatto (Argentina), Ronaldo Muñoz (Chile), Leonardo Boff (Brasil), Raül Vidales (México).

El autor que ha recibido gran atención, fue el argentino Enrique D. Dussel, a pesar de que la mayoría de sus publicaciones fueron escritas durante su exilio en México. Su Historia de la Iglesia en América Latina $(1972)^{25}$ sirvió como modelo para la «Comisión de Estudio sobre la Historia de la Iglesia en América Latina» (CEHILA), la cual posteriormente publicó la Historia de la Iglesia en Latinoamérica en diez volúmenes,

17. Maria Celina D’Araújo, y Celso Castro, Ernesto Geisel (Rio de Janeiro: Fundacao Getulio Vargas, 4. ed. 1997), 389.

18. No. 96 del Concilium (junio 1974) incluye las principales lecciones.

19. TeologíaTeologíaTeologíaTeología de la Liberación (Salamanca: Ediciones Sigueme, 1972).

20. Buenos Aires y México: Ediciones Carlos Lohlé, 1975.

21. Opressión - Liberación. Desafíos a los cristianos (Montevideo: Tierra Nueva, 1971).

22. Salamanca: Sigueme, 1973.

23. Towards a Theology of Liberation (Washington: Corpus Books, 1969). Por uma Teologia da Liberacao (Sao Paulo: Fonte Editorial, 2012).

24. A fe em busca de eficacia (São Leopoldo: Sinodal, 1976).

25. Madrid: Mundo Negro-Esquila Misional, 1992). 
desde la perspectiva de los oprimidos. Además, Dussel, Eduardo Hornaert y José Oscar Beozzo fueron de gran importancia en este proyecto. ${ }^{26} \mathrm{El}$ desarrollo político en América Latina (golpes de estado, torturas, deportación) impactó grandemente en la teología de la liberación. La liberación se entiende como la lucha persistente de los pueblos latinoamericanos, en contextos de persecución y opresión. Mientras que algunos consideraron que los estados de seguridad nacional darían lugar a una disminución de la teología, ocurrió lo contrario. La teología de la liberación se expandió y se difundió aún más. El movimiento popular y las Comunidades de Base recogieron estas ideas, especialmente en Brasil, México, El Salvador, Perú, Chile y Bolivia.

La teología de la liberación se convirtió cada vez más en una reflexión sobre la praxis de los pobres, quienes se habían organizado en asociaciones y movimientos ${ }^{27}$, más cerca de la religiosidad popular y no únicamente un reflejo de los intelectuales. Nuevos teólogos de la liberación surgieron, como Clodovis Boff y Joao Batista Libanio (Brasil), Jon Sobrino (El Salvador), y los exégetas bíblicos como Carlos Mesters, José Comblin, Jorge Pixley, Gilberto Gorgulho, Ana Flora Anderson y Milton Schwantes.

La teología de la liberación se difundió sobre todo por medio de folletos y transcripciones de conferencias. Los mismos teólogos no tenían prácticamente medios económicos a su disposición, y la mayoría muy poco acceso a la enseñanza en las facultades teológicas. Además, en los pocos casos que ejercieron la enseñanza, fueron prohibidos, como en Río de Janeiro, donde se prohibió a Cardinal Eugenio Sales y Clodovis Boff la enseñanza en su diócesis. Por esta razón, el pensamiento teológico se encontraba más fuera de las facultades que dentro de ellas. Otro poderoso medio para la difusión de teología de la liberación fue a través de las canciones religiosas.

Las reacciones contra la teología de la liberación fueron múltiples. El criticismo alcanzó un pico después de la publicación de Leonardo Boff: Iglesia, Carisma y Poder. ${ }^{28}$ Alertó al cardenal Joseph Ratzinger en Roma. Pero ésta teología trajo muchas bendiciones al contexto en el cual vivíamos, para las congregaciones y por sus Kairos. Se hizo un intento de hacer teología en la tierra para concretizar la verdad y así como crear una verdad liberadora. Los explotados, los exiliados, los oprimidos estaban agradecidos por estas expresiones de teología contextual. Sin embargo, la historia de la iglesia nos enseña que las teologías contextuales pueden ser temporales. Por esta razón, fue importante que Gustavo Gutiérrez colocara la teología de la liberación como «teología de la vida».

Mucho ha cambiado desde la década de 1980, tal como el aumento de teologías más conservadoras, la espiritualidad interior, y la despolitización. Lo que quedó fue una vez más «pan y circo». La teología ya no se convirtió en la sal de la tierra; no hacía daño, y fue como la crema batida sobre un pastel sabroso. No exige nada, no provoca nada. Podría ser el momento para preguntar acerca de la encarnación de Dios, y para descubrir de nuevo la teología de la cruz como nuestro proprium.

26. Ver Duncan A. Reily, «A História da Igreja depois da Teologia da Libertação» en A maioridade da Teología da Libertação (Estudos de Religião 6, no 6, São Paulo, 1989), 119-135.

27. Ver Franz Weber, Gewagte Inkulturation: Basisgemeinden in Brasilien: eine pastoralgeschichtliche Zwischenbilanz (Mainz: Mathias-Grünewald-Verlag, 1996).

28. Igreja: Carisma e Poder (Petrópolis: Vozes, 1981). 


\section{La teología de la cruz de Lutero}

Para San Pablo, de quien Lutero toma la teología de la cruz, una completa y nueva comprensión de Dios se revela a través de la cruz de Jesús. El conocimiento de Dios se convierte indisolublemente con la cruz. La sabiduría de Dios se revela a través de esta locura y necedad, revelada en la ocultación. El poder de Dios se perfecciona en la debilidad, la vida de Dios se convierte en poderosa en la muerte de su hijo. La revelación de Dios convierte todos los valores a su alrededor. Dios escoge lo que es humilde y sin valor en el mundo. La vida cristiana y la vida en la iglesia solo puede existir bajo la figura de la cruz, de lo contrario, no es una vida en el seguimiento de Jesús.

Lutero hizo de esta visión paulina la llave hermenéutica de su teología. En La disputación de Heidelberg (1518), Lutero defendió la tesis de que Dios no quiere ser comprendido en lo que es invisible, sino en lo que es visible y manifiesto (visibilia). De lo contrario, la teología no es nada. Porque Dios ha hablado, podemos hablar de Dios. Debido a que Dios se reveló a sí mismo sabemos dónde hay que mirar. En su interpretación del Magnificat (1521), Lutero escribiría que Dios mira «solamente en las profundidades, no a las alturas» y «cuanto más lejos uno está por debajo de él, mejor Él se ve» (WA 7,541).

Para Lutero, la revelación de Dios es una revelación indirecta. Como Moisés, solo vemos a Dios desde atrás, sino que oímos y vemos lo que Dios escucha y ve: «He visto la aflicción de mi pueblo que está en Egipto, y he oído su clamor y llanto a causa de sus opresores; Conozco sus sufrimientos» (Éxodo 3: 7). Reconocemos a Dios «a través del sufrimiento y de la cruz», es decir, Dios solo puede ser encontrado en el sufrimiento y en la cruz (WA 1,362, 28f.). Pero no solo el sufrimiento y la cruz de Cristo, sino también el sufrimiento y la cruz de sus seguidores. Ambos pertenecen juntos. La cruz de Cristo no es cualquier cruz; es la cruz de Dios en este mundo. En este cruce se hace evidente cómo las cosas se interponen entre Dios y el mundo. Por tanto, cada relación con Dios, debe tener en cuenta la realidad revelada por la cruz de Cristo. Únicamente aquellos que se encuentran en el sufrimiento y la cruz pueden reconocer a Dios.

Dios quiere ser comprendido en visibilia, que de acuerdo con Lutero incluye «humanidad», «impotencia» y «locura». Dios se reconoce en la ocultación, «en la humildad y la vergüenza de la cruz» (WA 1,362,12s). En el Cristo crucificado, Dios se manifestó en el encubrimiento. "Vivimos en el ocultamiento de Cristo, es decir, en la confianza desnuda de su misericordia». (WA 1,357,3).

El sufrimiento está íntimamente relacionado con este tipo de teología. Un teólogo de la cruz no mira hacia arriba, sino más bien en la dirección donde la humanidad, la impotencia y la locura se encuentran. Cuando la gente busca una vida segura, no están abiertos a esta predicación tonta, que re-evalúa todos los valores:

«Porque el evangelio destruye lo que es, hace que el poderoso caiga, se trae abajo la sabiduría y los convierte a la nada, en impotencia, en locura, porque enseña la humildad desde la cruz». (WA 1,617, 7ff). 
El viejo Adán tampoco puede entender las Escrituras, ya que solo desde la cruz de Cristo las Escrituras pueden ser entendidas. Por esta razón, Lutero llama a una verdadera enseñanza la sabiduría de la cruz . (WA 5,372,30f).

La antítesis de la teología crucis, era para Martín Lutero la teología de la gloria o la especulación religiosa. La cruz simplemente no puede alojarse o acomodarse en un edificio de ideas. La cruz al menos puede mostrar que Dios está oculto. Aunque escondido, Dios quiere ser reconocido. A través de la cruz, vemos «desgracia, pobreza, muerte y todo lo que se nos muestra en el sufrimiento de Cristo» (WA 5,108,1ff.). Dios es reconocido en la «humillación» (WA 1,353,21). En otras palabras, se nos ha dado la sabiduría de la cruz, con el fin de reconocer a Dios «en la forma opuesta»: Dios hecho humano. No es una especulación, la omnipotencia de Dios se expresa en el Dios crucificado.

Dios solo puede ser reconocido en la pasión; pues las obras de Dios tienen características de pasión. El poder de Dios se manifiesta en la debilidad. Además, la naturaleza de este Dios es anti-especulativa. Lutero va tan lejos como para afirmar: «Nada se parece más a la nada que no sea Dios mismo. Esta sabiduría de los santos y el misterio que se oculta a los sabios son revelados a los humildes». (WA 43,392).

La revelación no puede ser simplemente leída de la historia, en la que el pecado gobierna. Sin embargo la santidad de Dios, se opone al pecado y donde quiera que Dios se encuentre, los valores del mundo son revaluados. Lutero exige apartarse de la filosofía theologia gloriae y volver al Cristo crucificado. Esa filosofía de gloria lleva a la gente lejos de la cruz de Cristo y les anima a convertirse en autosuficientes (WA 5,107). Esta filosofía no tiene en cuenta el «anhelo ardiente de la creación» (Ro 8:19) y, por lo tanto, no puede comprender la realidad, no conoce ninguna necesidad de redención. No tiene oídos para el luto y el llanto de la creación.

Por el contrario, una sacra filosofía debería ser completamente escatológica. La cruz se convierte en el juicio de todos los pensamientos y las obras humanas. Únicamente cuando las personas llegan al camino de los desatinos, caminan a la cruz. Esta revela la falsedad filosófica de la glorificación humana y solo la sabiduría de la cruz reconoce la profundidad de las necesidades humanas. En la cruz toda concepción humana de Dios se convierte en nada, cada proyección humana de Dios llega a su fin. ¡La cruz pone todo a prueba! lo significa que la cruz es el juicio de nuestros pensamientos y obras. Esta se refiere a la reversión de las intervenciones humanas y los desatinos toman sentido. Cuando descendemos a toda ilógica del Cristo crucificado, estamos recorriendo el camino de la cruz. El uso del intelecto todavía se valora, pero solamente en la medida en que se reconoce como el trabajo humano. La razón es una «cosa peligrosa» (WA 9,187,5ss.), y no es capaz de ver el mundo y su realidad desde la perspectiva de la cruz.

Teología crucis revela el conflicto que hay en el mundo. Esto es la humanidad siempre querrá seguir la promesa hecha por la serpiente, «iUsted será como Dios!» El teólogo de la cruz debería decir las cosas como son. Debemos dejar de buscar «una sabiduría y piedad fuera de Cristo» (WA 2,113,26). Cuando el anuncio, de la iglesia, deja de ser un obstáculo entre los cristianos y la sociedad, entonces se ha traicionado el Evangelio (WA 2,601,25). El Evangelio es un obstáculo, un escándalo. En la cruz aprendemos que no 
hay otras maneras que vivir; que «en la confianza desnuda de la misericordia de Dios» (WA 1,357,3).

La teología de la cruz es práctica. Mientras que la teología de la gloria mantiene a la gente en un estado de contemplación, la teología de la cruz les sumerge en la decisión de fe. Lutero en un debate con Erasmo, afirmaba que el Espíritu Santo no es escéptico, ni deja los fieles en una actitud de contemplación, sino que les lleva a una decisión de fe. Solo mediante la participación en el sufrimiento podemos entender la cruz de Cristo y vivir la vida frente a la muerte. Por lo tanto, la vida cristiana, de acuerdo con Lutero, es una vida oculta. Esto implica participar concretamente en el sufrimiento de Cristo, al experimentar el desamparo, la debilidad y la desesperanza.

La vida cristiana está sufriendo por ser discipulado, ya que se centra en un evento concreto, la consecuencia directa de un acontecimiento, que toma lugar inmediatamente en el medio de la historia. Por lo tanto, el sufrimiento o discipulado no es ascetismo. Eso brota de la encarnación de Dios en este mundo, y es eminentemente teológico. Es una señal de la conexión de los cristianos con Cristo y viceversa.

«La pasión de Cristo no debe ser recibida a través de palabras y formas, pero sí con la vida y la verdad (WA 2,141,37f.), ... no en desiertos remotos, lejos de la sociedad, pero en medio de negocios y la política» (WA 43,214,3ff).

El cristiano que participa en el sufrimiento de Cristo atrae la hostilidad del mundo, esto a su vez es un signo de imitación auténtica, del verdadero discipulado (WA 1,214,1ss.), porque el Evangelio, la palabra de la cruz como un escándalo, suscita rencillas y lucha.

Para Lutero, la vida bajo la cruz se caracteriza por la humildad, la aflicción y la oración, pero «La humildad es el único salvador» (WA 4,473,17) y establece el amor al prójimo como límite para la humildad. Hay casos en que la injusticia es una violación al deber del amor (WA 5,233,33ss.). En su texto sobre el Magnificat, Lutero se ocupó intensamente de la humildad.

Humildad no es más que un estado descuidado, menospreciado y moderado, así como los hombres pobres, enfermos, con hambre y sed, en la prisión, sufriendo y muriendo. (WA 7,556,16 ff.). ¿Cómo se debe imputar tal orgullo y vanagloria, a esta Virgen pura y recta, como si ella se jactaba de su humildad ante la presencia de Dios? La humildad es la más alta de todas las virtudes, y nadie podría presumir de poseerla. Es Dios quien conoce la humildad. Sólo él lo juzga y lo trae a la luz; de modo que nadie sabe menos de la humildad, que aquel que es verdaderamente humilde. (WA 7,560,7ff.).

Pero la humildad no debe ser vista como mérito ante Dios. No debe ser la humildad honrada, solo la gracia de Dios. (WA 7,561, 16ss.).

\section{La teología de la cruz en relación con la teología de la liberación}

Tanto la Teología de la cruz como la Teología de la liberación no se deben considerar resultados de consideraciones teóricas, sino como teologías prácticas. Ambas tienen que ver con una cristología desde abajo, porque Dios radicalmente llegó a los que estaban «abajo». 
El sufrimiento y el Cristo crucificado han ocupado una posición central en la vida de las personas, que sufren en toda América Latina, en la vida de los pobres. Una «mediación de la cruz» surgió de las Comunidades de Base. El Cristo crucificado llegó a estar presente en el sufrimiento y la vida de los pobres, ahora Dios es reconocido.

Las imágenes de Cristo en América Latina no pueden entenderse al margen de la colonización y los gobernantes ibéricos. Ser un colonizador y ser cristiano estaba interconectado. Los estados de España y Portugal trajeron a Cristo a lo largo de su camino y con nuevas llegadas a Latinoamérica. Cristóbal Colón se convirtió en el portador de Cristo. En el nombre de Cristo, la conquista, el asesinato y el bautismo eran llevados a cabo al mismo tiempo. No es casualidad que Cristo se presentara como derrotado, como el siervo sufriente de Dios. Así, el Viernes Santo se convirtió en el día más importante del calendario religioso. Además, los juegos de pasión atraían a las multitudes ante la idea: «O Senhor Morto», el «Señor muerto», interpretada como una la devoción religiosa. Por ejemplo, el sábado de Pascua adquiere la tradición de golpear a un muñeco que representa a Judas, lo cual parece aún más importante que la fiesta de la resurrección de nuestro Señor. La figura central es el Señor abusado y torturado del Viernes Santo. En este caso el Señor se identifica con las personas y viceversa. El Cristo crucificado es la imagen de un pueblo que sufre: él es indígena y esclavo; sin tierra, campesino y jornalero. De esta manera, un sentimiento de resignación se apodera de las personas. La agonía de Cristo se convierte en la agonía del pueblo y en la agonía de las personas está la agonía de Cristo.

La identificación negativa prevalece. Mujeres, indígenas y obreros se ven a sí mismos en Cristo. Es el destino y ni siquiera el Hijo de Dios puede escapar de eso. Si Dios mismo debe sucumbir al destino, ¿por qué deberíamos quejarnos? El «Señor muerto» sacraliza la historia moldeada por la conquista y por los siglos de explotación. Él justifica su propio sufrimiento, antes de su muerte; el Dios que desea la vida. En la religión Umbanda brasileña, este Cristo finalmente se convierte en lo que es: una deidad entre otros. Se celebra el sufrimiento.

Amenazadora e importante es la otra imagen de Cristo, el Celestial gobernante. Él lleva los símbolos de los reyes de Portugal y España. ¿Con qué facilidad pueden ser confundidos: el Rey se convierte en Cristo y Cristo se convierte en Rey? Con insignias reales Cristo da legitimidad a las acciones políticas del gobernador y su fidelidad se convierte en la lealtad al rey y viceversa. Cristo se convierte en un ministro de la propaganda para el rey. Por todas partes en América Latina el creyente se enfrenta durante las misas con el origen de su dependencia. Con medios espirituales se implementa una dependencia política. La sujeción a los explotadores se entiende como un regalo de Dios. Pero este Cristo es mucho peor que el primero, pues no tiene ni siquiera que sufrir. El indígena se vuelve hacia el «Señor muerto», en lugar de al monarca celestial.

«Jesucristo, el esclavizador» sería un título más apropiado para la cristología que surgió de estas dos figuras de Cristo. Aquí Dios realmente no se convirtió en carne, se puso de parte del poder político, así ni Dios ni los gobernantes podrían estar en contradicción. Los cristianos guardaban silencio. El «Señor muerto» y el Monarca Celestial mantuvieron el silencio sobre el sufrimiento de las personas. Eso se pudo notar en los años entre 1970 y 1980. 
Ninguna deidad dijo nada acerca de la concentración de tierras en manos de unos pocos. En 1970, el 11\% de la clase rica en Brasil, era dueña del 44,3 de la tierra, mientras que los más pobres, el 50\% poseía el $22 \%$ de la tierra. Ya en el año de 1980 , el $11 \%$ de la clase rica poseía el $82,3 \%$ de la tierra, mientras que el 50\% los más pobres, poseían solamente el 14,9\% de la tierra. Lo mismo pasó con la distribución de los ingresos: En 1960, los más pobres $70 \%$ recibían el $21,2 \%$ de los ingresos, mientras que el $16 \%$ de los ricos, recibían el 79,8\% de los ingresos. En 1980, el 70\% los más pobres, recibían el 15,4\% de los ingresos, mientras que el 16\% más rico aumentó sus ingresos hasta el $84,6 \%$.

En el mismo periodo se mantuvieron en silencio sobre las consecuencias: 10 millones de niños viven en las calles y no conocen ni padre ni madre. Además, 45 niños murieron cada hora (1080 por día; más de 400.000 por año). 11 millones de personas estaban sin empleo. El salario mínimo era equivalente a 74 DM (como en 30.10.1987) un mes, cuando debería haber sido 444 DM. $30 \%$ (según algunas versiones, un $40 \%$ ) de la población era analfabeta. En un corto período, 15 millones de habitantes rurales se trasladaron a las grandes ciudades. En 1960 el 70 \% de la población vivía en el campo. En 1980 exactamente lo contrario: el $70 \%$ de la población vivía en las ciudades, la mayoría de ellos en los barrios marginales.

Cuando América Latina estaba empezando a alejarse de un Cristo masoquista y represivo, esto no sacudió la cruz, sino más bien la imagen específica de Cristo. La cruz de Cristo no es un signo de impotencia, sino un signo de poder de aquel que entregó el poder y se convierte en poderoso en el poder de los pobres. La cruz es un signo de la miseria, y por esa misma razón, una protesta contra la miseria. Jesús terrenal y el Cristo bíblico se levantan contra una distante concepción.

¿Qué hay detrás de este cambio? En un momento histórico en el que América Latina tuvo conocimiento de su existencia cultural, aprendió de su dependencia y dolorosamente descubrió que su población había sido víctima de una injusticia histórica, la iglesia comenzó a llevar a cabo su misión profética. La situación de la gente llevó a la iglesia a descubrir aspectos de la fe, de las Escrituras y de la doctrina cristiana que había sido olvidada durante mucho tiempo. En otras palabras, nada fundamentalmente nuevo fue descubierto. Lo que ocurrió fue simplemente un retorno al Evangelio debido a la difícil situación del pueblo. El punto de partida de la teología ya no era lo que los teólogos habían dicho con anterioridad, sino más bien lo que la realidad misma mostraba. Como fue formulado por Enrique Dussel ${ }^{29}$, quien se refirió que la realidad nos mostró una situación de dependencia política, económica y pedagógica.

Sin embargo, aprendemos que Dios se reveló en una situación de política, económica, y de dependencia pedagógica. Dios se convierte encarnado en esta humildad. Él escoge precisamente lo inútil y lo humilde en el mundo. Dios escoge un entorno sociohistórico específico en el cual nacer; no porque ama la dependencia y la opresión, sino porque ama a aquellos que viven en esta realidad. El entorno en el que se revela expresa

29. Enrique D. Dussel, Para uma Ética da Libertação Latino-Americana, Vol 1: Acesso ao Ponto de Partida da Ética (São Paulo and Piracicaba: Edições Loyola and Editora, Unimep, 1977). 
algo acerca el amor de Dios. Dios ama a los pobres, a los oprimidos, a las mujeres, a los niños, mas no la pobreza ni la opresión. Bienaventurados los pobres, no la pobreza. Dios muestra su solidaridad con aquellos que viven en una determinada situación, no con lo que trae consigo la situación.

El entorno en el que Dios nació, vivió, fue crucificado y resucitado es humilde (Fil. 2:6-7). Cristo toma el lugar de los oprimidos como alguien que está oprimido. Se convierte en un servidor; es decir, asume el lugar socio-político, cultural y las condiciones económicas de aquellos que han sido privados de sus derechos fundamentales. Cristo viene a ser como el indígena, el africano, el asiático, el abusado, la mujer, el niño. Cristo es atrapado por el pecado y por el sistema, sin caer presa de nadie.

En el sufrimiento de las personas en América Latina, reconocimos el sufrimiento de Dios con la creación. En la protesta de la gente, oímos el grito de Dios. Hemos aprendido de nuevo a reconocer a Dios en el sufrimiento y en la cruz. La cruz de Dios nos reveló nuestra realidad, mientras que nuestra realidad revela todo lo que la cruz de Dios implica. Aquí se hizo evidente lo que Pablo y Lutero querían decir, en el sentido de que Dios solo podía ser reconocido en el sufrimiento y en la cruz por aquellos que se encuentran en el sufrimiento y en la cruz.

\section{Conclusiones}

¿Cómo es Dios? ¿Cómo hablamos de Dios en América Latina? Dios tal como se revela en el Cristo crucificado, allí vemos humanidad, debilidad, necedad. Hemos aprendido que si queremos ver a Dios, debemos mirar hacia donde se encuentran la humanidad, la debilidad y la necedad (Mateo 25).

Esta aparición de Dios se anticipa a cualquier especulación religiosa. Dios reveló que la cruz es antiespeculativa. En la cruz el «impío» toma lugar la infamia, la pobreza, y la muerte. La cruz dio a conocer toda la profundidad de la situación humana en América Latina. Eso abrió el oído para escuchar el gemido y el anhelo de redención (Romanos 8). La cruz es el juicio contra una gloria humana falsa que subsistía en la explotación y en la opresión. Es un grito de la incomprensión a la comprensión. Se convirtió en un grito de libertad. Se convirtió en un grito de guerra para ser como Dios; es decir, para seguir el camino del sufrimiento con el fin de permitir a la vida. El camino de la libertad únicamente puede ser caminado bajo la cruz.

También se aclaró que el modo de pensar de la serpiente («Vas a ser como Dios!») no es el modo de Dios.

Por eso la teología de la liberación ha sido escandalosa. Tiene el valor de la parcialidad de Dios. Sus teólogos eran hombres y mujeres de la gente común en América Latina que se enfrentaron a su experiencia de humildad con la humillación de Dios. Sus ideas teológicas destacaron también la política, la tierra y en particular, a los «pobres». Sus exégetas eran personas analfabetas que se dieron cuenta de la cercanía de Dios, mediante la experiencia e interpretación de su «bendita» situación de opresión. Por lo tanto, ellos querían demostrar que la interpretación de la Palabra no se 
limita a una teología académica. ${ }^{30}$ A partir de la parcialidad de Dios se enteraron de que el Hijo de Dios fue derribado por los intereses de la clase dominante y que su cruz es una protesta contra las estructuras sociales que apoyan la opresión. Los textos de la teología de la liberación fueron escritos en la «barriada», y no estaban destinados a ser cómodos.

Por consiguiente, al igual que la teología de la cruz, la teología de la liberación también se convirtió en una ciencia práctica y motivó a la gente en la decisión de la fe. Al igual que la teología de la cruz, la teología de la liberación fue una vida bajo la cruz. Solo a través de la compasión por el sufrimiento del mundo, puede ser entendida la cruz de Cristo, y no desde una perspectiva de espectadores pasivos o torre de marfil.

Por esta razón, el entorno natural de la teología de la liberación fueron congregaciones locales que vivieron en el rostro de la muerte. Por lo general, este tipo de comunidades de base se reunían en edificios feos y desagradables. Ellos estaban dispuestos a asumir la vergüenza de Cristo en su sufrido discipulado. Aquí, el desamparo, la debilidad y la angustia son experimentadas, pero solo en la esperanza pascual. La Pascua es el éxodo de la muerte a la vida y la voluntad de Dios no es la muerte, sino la vida. Sin embargo, en el discipulado de la cruz, sabemos que el camino a la vida pasa a través de la muerte. El Resucitado es el Crucificado.

Desde esa perspectiva, el sufrimiento de las personas recibe un nuevo significado: sufriendo en el discipulado del Crucificado. Este sufrimiento se lleva a cabo no en el desierto, alejado de la sociedad, sino dentro de la economía y de la política. El camino hacia la libertad que la teología de la liberación propone es largo. Este camino que trajo sobre el mundo la hostilidad, también se encuentra dentro de la iglesia. Por lo tanto, las declaraciones «eclesiásticas» de oposición no deberían asustarnos o sorprendernos. El camino de la teología de la liberación como una vida bajo la cruz es una vida en la opresión, en la tentación, en la aflicción, pero también en virtud de la oración constante. Se vive en la conducta ética de la justificación por la gracia y la fe, lo que hace posible superar el egoísmo y la falta de amor.

La conducta liberadora del cristianismo se deriva de la certeza del perdón de Dios y en una orientación completamente renovada del Espíritu Santo, que nos enseña a anhelar lo que es divino y no humano (Mateo 6:33). Solo aquellos que han aprendido el amor del Evangelio tienen el valor de luchar por la libertad. Ellos son capaces de amar. El amor es diaconía, es la fuerza dinámica de la teología de la liberación.

En algunos países de América Latina, la economía y el nivel de vida han cambiado considerablemente. Sin embargo, los pobres todavía están ahí. Por otra parte, bajo la regla del mercado, el discurso de algunas iglesias «cristianas» también ha cambiado. Las relaciones entre las personas se han convertido en «transacciones comerciales». La

30. Entre los numerosos títulos publicados en ese momento están: Ernesto Cardenal, Das Evangelium der Bauern von Solentiname: Gespräche über das Leben Jesu in Lateinamerika (Wuppertal: Jugenddienst-Verlag, 1976); Ernesto Cardenal, Das Buch von der Liebe: Lateinamerikanische Psalmen (Hamburg: Siebenstern Taschenbuch Verlag, 4. ed., 1976). Antonio Reiser y Paul Gerhard Schoenborn, ed., Basisgemeinden und Befreiung: Lesebuch zur Theologie und christlichen Praxis in Lateinamerika (Wuppertal: Jugenddienst-Verlag, 1981). 
predicación se concentra en el establecimiento de una relación de do ut des entre las personas y Dios. El negocio de las indulgencias ha regresado. La teología de Lutero de la cruz puede hablar con nueva relevancia aquí.

* Traducción del inglés: Rodolfo Mena, Costa Rica

\author{
ABSTRACT \\ Rediscovering the Theology of Martin Luther of the Cross
in the Theology of Liberation context
}

To the radicalness of the Reformation belongs a new image of God that Luther presented at the Heidelberg disputation and that continues determining his theology. God has the face of the crucified and looks radically down (Magnificat). However, in Lutheranism a doctrine of justification was presented that ignores Luther's central intention. The aim of this investigation is to show how, in conversation with liberation theology, Luther's theology of the cross gained new importance in the Latin American context.

Keywords: Reformation Theology, image of God, doctrine of justification, Theology of the Cross, Liberation Theology.

\title{
RÉSUMÉ
}

\section{La redécouverte de la Théologie de la Croix de Martin Luther dans le contexte de la Théologie de la Libération}

Dans sa Dispute de Heidelberg, Luther présente une nouvelle image de Dieu qui appartient aux radicales de la Reforme et qui a continué à déterminer leur théologie. Dieu a le visage du Crucifié et regarde radicalement en bas (Magnificat). Cependant, le luthéranisme a représenté une doctrine de la justification qui a abandonné l'intention centrale de Luther. Le but de cet article est d'enseigner comme la théologie de la croix de Luther s'est mis en relief de nouveau dans le dialogue avec la Théologie dans le contexte latino-américain.

Mots-clés : Théologie de la Reforme, image de Dieu, doctrine de la justification, théologie de la croix, théologie de la Libération.

\section{Bibliografía}

Alves, Rubem A. Towards a Theology of Liberation. Washington: Corpus Books, 1969.

Alves, Rubem A. Por uma Teologia da Libertação. São Paulo: Fonte Editorial, 2012.

Altizer, Thomas J.J. y William Hamilton. A Morte de Deus- Introdução à Teologia Radical. Rio de Janeiro: Editora Paz e Terra, 1967.

Assmann, Hugo. Opresión - Liberación. Desafíos a los cristianos. Montevideo: Tierra Nueva, 1971.

Assmann, Hugo. Teología desde La Praxis de La Liberación. Salamanca: Sigueme, 1973.

Boff, Leonardo. Igreja; Carisma e Poder. Petrópolis: Vozes, 1981.

Bonhoeffer, Dietrich. Resistência e submissão. Rio de Janeiro: Paz e Terra, 1968. 
Concilium, No. 96 (1974).

Confederação Evangelica do Brasil, ed. A Conferencia do Nordeste. Cristo e o Processo Revolucionario Brasileiro. 2 Vol. Rio de Janeiro: Editora Loqui, 1962.

Cox, Harvey. A Cidade do Homem. A secularização e a urbanização na perspectiva teológica. Rio de Janeiro: Pax e Terra, 1965.

D’Araújo, Maria Celina y Celso Castro. Ernesto Geisel. 4. ed., Rio de Janeiro: Fundação Getulio Vargas, 1997.

Dreher, Martin N. A lgreja Latino-Americana no Contexto Mundial. São Leopoldo: Sinodal, 1999.

Dussel, Enrique D. Para uma Ética da Libertação Latino-Americana. Vol 1: Acesso ao Ponto de Partida da Ética. Sao Paulo and Piracicaba: Edições Loyola y Editora, Unimep, 1977.

Dussel, Enrique. Historia de La Iglesia em América Latina: coloniaje y liberación (1492-1983). 5. ed., Madrid y México: Mundo Negro-Esquila Misional, 1983.

Friede, Juan. Bartolomé de las Casas, precursor del anticolonialismo. Su lucha y su derrota. México: Siglo XXI, 1974.

Gogarten, Friedrich. Verhängnis und Hoffnung der Neuzeit. Die Säkularisierung als theologisches Problem. Múnich y Hamburgo: Siebenstern, 1966.

Gutiérrez, Gustavo. A Theology of Liberation. Maryknoll: Orbis Books, 1973.

Käsemann, Ernst. Der Ruf der Freiheit. 4. ed., Tubinga: J.C.B.Mohr/Paul Siebeck, 1963.

Kierkegaard, Sören. Einübung im Christentum. Düsseldorf y Köln: Eugen Diederichs Verlag, 1951.

Kickhofel, Oswaldo (2011). Ernesto João Bernhoeft. Uma vida de fé, abnegação e júbilo - 1917-2001. Montenegro: s.e., 2011.

Metz, Baptist/J. Moltmann y W. Oelmüller. Kirche im Prozess der Aufklärung. Aspekte einer neuen «politischen Theologie». München/Mainz: Chr. Kaiser y Grünewald Verlag, 1970.

Miguez Bonino, José. A fé em busca de eficácia. São Leopoldo: Sinodal, 1976.

Moltmann, Jürgen (1966). Theologie der Hoffnung. Untersuchungen zur Begründung und zu den Konsequenzen einer christlichen Eschatologie. 6. ed. Múnich: Chr. Kaiser-Verlag, 1966.

Prien, Hans Jürgen. Die Geschichte des Christentums in Lateinamerika. Gottinga: Vandenhoeck y Ruprecht, 1978.

Rendtorf, Trutz y Heinz Eduard Tödt, ed. Theologie der Revolution - Analysen und Materialien. 4. ed. Fráncfort del Meno: Suhrkamp Verlag, 1970.

Reily, Duncan A. «A História da Igreja depois da Teologia da Libertação» en A maioridade da Teología da Libertação (Estudos de Religião 6, No. 6). São Paulo, 1989, 119-135.

Segundo, Juan Luis. Liberación de la Teología. Buenos Aires y México: Ediciones Carlos Lohlé, 1975.

Shaull, Richard. Transformaciones profundas a la luz de una Teología Evangélica. Petrópolis: Vozes, 1966.

Sölle, Dorothee. Stellvertretung. Ein Kapitel Theologie nach dem «Tode Gottes». Gütersloh: Mohn, 1965.

Von Loewenich, Walther. Luthers Theologia Crucis. Bielefeld: Luther-Verlag, 5.ed., 1967.

Weber, Franz. Gewagte Inkulturation. Basisgemeinden in Brasilien: eine pastoralgeschichtliche Zwischenbilanz. Mainz: Mathias-Grünewald-Verlag, 1996. 